\title{
SUBSTITUTION AND PRIMARY DEPENDENCE STUDIES IN ANIMALS
}

\author{
JAMES H. WOODS and DEBRA E. GMEREK
}

Department of Pharmacology, M6322 Medical Science Building, University of Michigan, Ann Arbor, MI 48109-0010 (U.S.A.)

\section{SUMMARY}

The mixed agonist-antagonist analgesics buprenorphine, butorphanol, nalbuphine, pentazocine and picenadol were compared to the prototype mu and kappa agonists morphine and Mr 2033, respectively, in the following tests in rhesus monkeys: overt behavioral effects upon acute administration in drug-naive animals; discriminative stimulus properties in monkeys trained to respond to either etorphine or ethylketazocine; self-administration of the test agent relative to codeine; single dose suppression and precipitation in withdrawn and non-withdrawn morphine-dependent monkeys, respectively; and primary addiction studies in drug-naive animals. Whereas both buprenorphine and nalbuphine precipitate withdrawal in morphine-dependent monkeys, withdrawal following chronic administration of buprenorphine resulted in no observable signs of abstinence, while nalbuphine withdrawal was similar to that seen in morphine-dependent monkeys. Butorphanol, pentazocine and picenadol all produced mild dependence of the kappa-type; that is, natural withdrawal behavior similar to that seen following chronic Mr 2033 administration.

Key words: Mixed agonist-antagonist analgesic - Buprenorphine - Butorphanol - Morphine - Mr 2033 (UM 1072) - Nalbuphine - Pentazocine Picenadol Rhesus monkey - Dependence

\section{INTRODUCTION}

The profile of action of morphine has been well characterized in rhesus monkeys [e.g., 1,2]. Compounds with morphine-like agonist actions share the capacities to produce discriminative stimulus effects similar to morphine or etorphine, to reinforce responding and to suppress withdrawal in morphine-dependent monkeys. These properties are dose-dependent, stereoselective and naloxone-sensitive. Whereas the profile of action of kappa agonists is not as well defined, UM 1072 (Mr 2033), an $N$-furyl-suhstituted 
benzomorphan, can be used as a prototype kappa agonist. The effects of UM 1072 are different from those of morphine in that it does not share morphine-like discriminative effects, reinforced responding occurs only at low rates and it does not substitute for morphine in dependent monkeys [1]. UM 1072 does share discriminative effects with ethylketocyclazocine, however, in a dose-related, stereoselective and naloxone-sensitive manner [3]. Furthermore, chronic administration of UM 1072 produces dependence demonstrated by a withdrawal syndrome which is qualitatively different from that seen following chronic morphine administration. Thus, it is possible to clearly distinguish between opiate agonists at mu and kappa receptors. However, there are some opioids which do not have a clear-cut profile of effects. Mixed agonist-antagonist analgesics may or may not suppress or precipitate morphine withdrawal, depending on the dose of mixed agonist-antagonist and the duration of morphine dependence or abstinence. Furthermore, chronic administration of these compounds may or may not produce dependence of either the mu- or kappa-type.

The effects of five selected mixed agonist-antagonist analgesics will be discussed in relation to their activities in the following tests in rhesus monkeys: (1) overt behavioral effects upon acute administration to drugnaive animals; (2) discriminative stimulus properties in monkeys trained to respond on the drug key after (a) etorphine or (b) ethylketazocine; (3) self-administration of the test agent relative to codeine; (4) single dose suppression and precipitation tests in morphine-dependent monkeys; and (5) primary addiction studies in drug-naive monkeys. These five types of studies will be discussed in detail in turn. Morphine, as a prototype mu agonist, and UM 1072 ( $\mathrm{Mr} 2033$ ), as a prototype kappa agonist, are included for the purpose of comparison. The compounds selected for characterization are: buprenorphine, butorphanol, nalbuphine, pentazocine and picenadol. Their classification in terms of agonist actions at mu or kappa receptors, as well as their opiate antagonist effects will be discussed. Emphasis will be placed on the substitution and primary dependence studies.

\section{ACUTE EFFECTS IN NORMAL MONKEYS}

Normal (drug-naive) rhesus monkeys housed in groups of 4-6 were trained to receive subcutaneous injections. They were monitored by two experienced observers familiar with the individual animals. The appearance and behavior of the monkeys were noted by checking the presence of signs on score sheets. Stupor (the response of the monkeys to external stimuli), muscle relaxation (the appearance of the monkeys when stationary) and ataxia (the facility of the monkeys when moving) scores were given according the descriptions in Table I. It is not possible to distinguish between mu and kappa opioids by this test. Thus, morphine and UM 1072 both produced stupor and muscle relaxation in a dose-related manner (Figs. 1 and 2). However, naloxone reversibility indicates opiate receptor mediation 


\section{TABLE I}

SCALES BY WHICH MONKEYS WERE GRADED FOR STUPOR (ACCORDING TO THE ANIMALS' RESPONSE TO EXTERNAL STIMULI), GENERAL MUSCLE RELAXATION (ACCORDING TO THE POSITION THE MONKEYS TAKE WHEN S'I'A'IIONAKY) AND A'I'AXIA (ACCORDING 'TU 'I'HE FACILI'TY WI'TH WHICH THE ANIMALS MOVE)

\section{Grade}

\begin{tabular}{ll}
\hline & Stupor \\
Nos & No observable stupor \\
+ & Monkey appears to stare into space \\
$\mathrm{A}$ & Monkey is inattentive to ordinary movements of other monkeys \\
$\mathrm{A}+$ & Monkey is inattentive to ordinary movements of observers \\
$\mathrm{B}$ & Monkey responds only to loud noises in room \\
$\mathrm{B}+$ & Monkey responds only to opening of cage latch \\
$\mathrm{C}$ & Monkey responds only to loud noises near his ear \\
$\mathrm{C}+$ & Monkey responds only to touch \\
& \\
0 & Muscle relaxation \\
1 & No observable muscle relaxation \\
2 & Slight facial relaxation; jaw slackening, shoulder droop \\
3 & Pronounced facial relaxation; jaw slackening, shoulder droop \\
4 & Monkey must brace himself to sit up \\
& Monkey cannot sit \\
0 & Ataxia \\
1 & Noobservable ataxia \\
2 & Monkey misses step occasionally \\
3 & Monkey misses intended landing spot when jumping \\
\hline
\end{tabular}

of the overt behavioral effects of a given compound. Buprenorphine, butorphanol, nalbuphine and pentazocine caused dose-related mydriasis, stupor and muscle relaxation which could be reversed by naloxone. In contrast, the stupor, muscle relaxation and ataxia elicited by chlorpromazine or phencyclidine is not antagonized by naloxone (Gmerek, unpublished). Picenadol caused irritability as well as muscle relaxation and ataxia in normal rhesus monkeys. These effects were only transiently modified by naloxone.

\section{DRUG DISCRIMINATION STUDIES}

Rhesus monkeys were trained to discriminate etorphine $(0.00032 \mathrm{mg} / \mathrm{kg}$, s.c.) or ethylketazocine $(0.0032-0.0056 \mathrm{mg} / \mathrm{kg}$, s.c.) from sham injections as described previously [4]. Training and testing was done with a multipletrials procedure. Reinforcement with 10 banana-flavored pellets occurred after 100 consecutive responses on the injection-appropriate lever during 

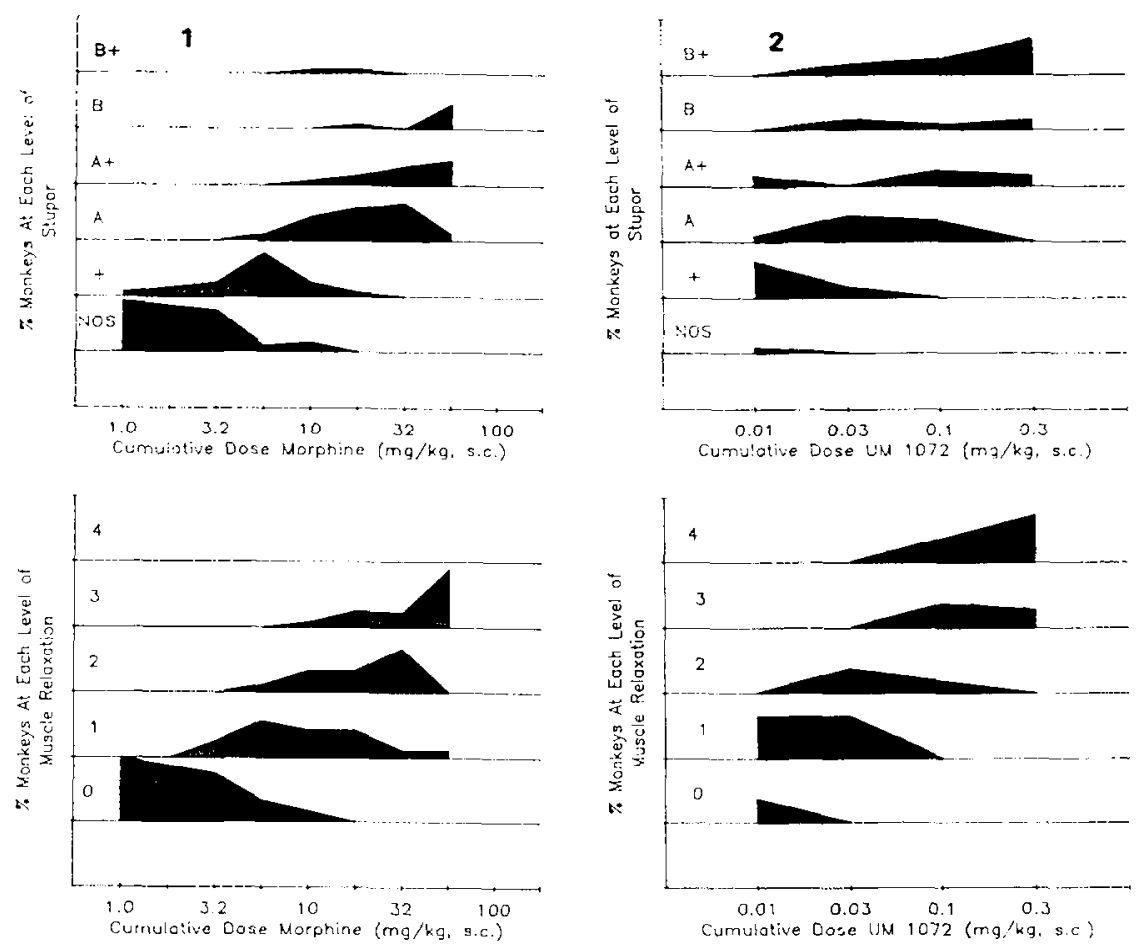

Fig. 1. The ef fect of morphine given in cumulative doses every $30 \mathrm{~min}$ to rhesus monkeys $(n=6)$ on stupor (top panel) and muscle relaxation (bottom panel). Each horizontal segment represents the percent of animals $(0-100 \%)$ showing the designated level of effect as described in Table I.

Fig. 2. The effect of UM 1072 ( Mr 2033) given in cumulative doses every $30 \mathrm{~min}$ to rhesus monkeys $(n=6)$ on stupor (top panel) and muscle relaxation (bottom panel) as in Fig. 1.

training, or either lever during testing. A criterion of at least $90 \%$ injectionappropriate responses on every training trial for 5 consecutive days was met prior to the first test. During testing, increasing cumulative doses of the test agent were given before consecutive trials of a daily session.

Table II shows the average dose of test compound which produced at least $90 \%$ drug-appropriate responding in monkeys trained to discriminate (a) etorphine from saline or (b) ethylketazocine from saline. The results indicate that buprenorphine, butorphanol and nalbuphine are similar to morphine in that they occasioned drug-appropriate responding only in the monkeys trained to discriminate etorphine, and not in the ethyketazocinetrained animals [4]. Picendadol did not produce drug-appropriate responding in the monkeys trained to discriminate ethylketazocine, but was not tested in the etorphine-trained monkeys. Pentazocine is unusual in that it did not produce drug-appropriate responding in monkeys trained to discriminate ethylketazocine [3] or etorphine. 
TABLE II

DOSES (mg/kg, s.c.) OF COMPOUNDS REQUIRED TO OCCASION $\geq 90 \%$ OF TOTAL SESSION RESPONSES ON THE DRUG-APPROPRIATE LEVER

\begin{tabular}{lll}
\hline Compound & Training Stimuli & \\
\cline { 2 - 3 } & Etorphine vs. saline & Ethylketazocine vs. saline \\
\hline Buprenorphine [4] & 0.05 & $-{ }^{\mathrm{a}}$ \\
Butorphanol [4] & 0.003 & - \\
Nalbuphine [4] & 0.07 & - \\
Pentazocine [3] & - & - \\
Picenadol & Not tested & - \\
Morphine [3] & 1.0 & 0.008 \\
UM 1072 [1,3] & - & \\
\hline
\end{tabular}

${ }^{a}$ Indicates no dose produced $\geq 90 \%$ drug-appropriate responses.

\section{SELF-ADMINISTR ATION STUDIES}

Monkeys were trained to self-inject codeine intravenously $(0.32 \mathrm{mg} / \mathrm{kg}$ per injection) as described previously [4]. Saline was used as a negative control. A number of doses of test agent were used until a maximum rate of responding was obtained, or until directly observable confounding behaviors (such as stupor) were produced. A fixed-ratio 30 schedule of intravenous drug delivery was used, with a 10 -min timeout condition in effect after each injection. The monkeys $(n=3)$ participated in twice daily sessions of 13 injections or $130 \mathrm{~min}$, whichever occurred first.

TABLE III

DRUG REINFORCED RESPONDING OF MONKEYS DURING SUBSTITUTION WITH TEST COMPOUNDS FOR THE TRAINING DRUG (CODEINE: $0.32 \mathrm{mg} / \mathrm{kg}$ PER INJECTION)

\begin{tabular}{lll}
\hline Compound & $\begin{array}{l}\text { Rate of responding } \\
\text { (\% maintained by } \\
\text { codeine) }\end{array}$ & $\begin{array}{l}\text { Optimal rate-maintaining } \\
\text { dose (mg/kg per } \\
\text { injection) }\end{array}$ \\
\hline $\begin{array}{l}\text { Buprenorphine [4] } \\
\text { Butorphanol [4] }\end{array}$ & 64 & 0.10 \\
Nalbuphine [4] & 39 & 0.003 \\
Pentazocine & 45 & 0.03 \\
Picenadol & $34,86^{\mathrm{a}}$ & $0.01,0.10$ \\
Morphine [3] & 33 & 0.10 \\
UM 1072 [1] & 57 & 0.10 \\
\hline
\end{tabular}

${ }^{a}$ Results from separate studies performed in 1977 and $19 \times 2$, respectively. 
Table III shows the relative potencies and efficacies of the compounds under investigation to maintain responding in monkeys trained to selfadminister codeine. Average control response rates for codeine and saline were 2.3 and 0.02 responses/s, respectively $[4,5]$. Morphine was self-administered at $57 \%$ of the rate maintained by codeine [5]. In contrast, the kappa agonist UM 1072 was self-administered at a very low rate: only $12 \%$ of that of codeine; similarly, ethylketazocine is self-administered at only $3 \%$ of the rate maintained by codeine [1]. Buprenorphine maintained a high rate of responding; butorphanol was self-administered but at rates only slightly higher than that of UM 1072; nalbuphine maintained selfadministration responding at rates intermediate between the mu-agonists buprenorphine and morphine, and the kappa agonists ethylketazocine and UM 1072 [4]. Picenadol was self-administered at low rates. The results of the self-administration studies with pentazocine are difficult to interpret. In earlier studies, pentazocine was self-administered at very low rates. However, a few monkeys tested in later studies consistently self-administered pentazocine at very high rates: close to those maintained by codeine. The effect of pentazocine thus appears to be idiosyncratic in this test. This is a novel phenomenon using the drug-reinforced responding protocol in that it is unusual to find some monkeys self-administer a compound at high rates while others do not self-administer it at all; that is, an all-or-none effect.

\section{EFFECTS IN MORPHINE-DEPENDENT MONKEYS}

Group-housed rhesus monkeys were made dependent by administering morphine sulfate $(3 \mathrm{mg} / \mathrm{kg}$, s.c.) every $6 \mathrm{~h}$ for at least 3 months. Withdrawal severity was assessed by two experienced observers familiar with the individual animals, as described previously by Deneau and Seevers [6] and Villarreal [7]. The presence of signs and behaviors were recorded on score sheets. Withdrawal scores increase with an increasing number and intensity of signs (Table IV). This system integrates into one withdrawal severity score the appearance and behavior of the monkeys and their responses to handling. The median withdrawal score of 14-h withdrawn morphinedependent monkeys was a ' 4 '. Withdrawal was assessed before the first injection and at 30-60-min intervals thereafter for $4-5 \mathrm{~h}$.

The suppression test determines the ability of a compound to overcome signs of withdrawal in dependent monkeys deprived of two consecutive maintenance doses of morphine. Opiate mu agonists suppress withdrawal in 14-h morphine-deprived monkeys in a dose-related manner (Fig. 3), whereas kappa agonists do not suppress withdrawal in deprived morphinedependent monkeys at doses which do not cause significant stupor [1]. UM $1072(0.01-0.3 \mathrm{mg} / \mathrm{kg}$, s.c.) does not suppress withdrawal in morphinedependent monkeys at doses which do not cause stupor scores (Table I) below 'B'. 
TABLE IV

SCALE BY WHICH MONKEYS WERE GRADED FOR WITHDRAWAL SEVERITY ${ }^{a}$

\begin{tabular}{|c|c|}
\hline $\begin{array}{l}\text { Withdrawal } \\
\text { score }\end{array}$ & Description of monkeys' behavior and appearance \\
\hline 0 & No observable signs of withdrawal \\
\hline $\begin{array}{l}1^{b} \\
2^{b}\end{array}$ & $\begin{array}{l}\text { Apprehension, avoiding one another, shivering, } \\
\text { irritability, quarreling, fighting, disrupted } \\
\text { social interactions }\end{array}$ \\
\hline $3^{c}$ & $\begin{array}{l}\text { Intention tremor, anorexia, piloerection, muscle } \\
\text { rigidity, aggression, holding of abdomen, sittting }\end{array}$ \\
\hline $4^{\mathrm{c}}$ & $\begin{array}{l}\text { on floor, abdominal defense reaction, apprehension } \\
\text { and aggression during handling }\end{array}$ \\
\hline 5 & $\begin{array}{l}\text { Extreme restlessness, assumption of peculiar } \\
\text { postures, severe diarrhea, penile erection and }\end{array}$ \\
\hline 6 & $\begin{array}{l}\text { masturbation, continual crying, lying on side, } \\
\text { ex treme abdominal cramping, convulsions }\end{array}$ \\
\hline 7 & Docility in an excitable animal, death \\
\hline
\end{tabular}

The precipitation test determines the ability of a compound to elicit withdrawal signs in non-withdrawn dependent monkeys and is an indication of mu opioid receptor antagonist activity. Naltrexone precipitates withdrawal in a dose-related manner when given $2 \mathrm{~h}$ after the last morphine injection in dependent monkeys (Fig. 4).

The effects of the compounds under investigation in the single dose suppression test is summarized in the middle column of Table V. Buprenorphine did not suppress withdrawal in 14-h morphine-deprived animals at doses of $0.001-0.1 \mathrm{mg} / \mathrm{kg}$. Higher doses of buprenorphine $(0.17-0.3$ $\mathrm{mg} / \mathrm{kg}$ ) exacerbated withdrawal in abstinent monkeys. Butorphanol was similar to buprenorphine in that at low doses $(0.4-3.2 \mathrm{mg} / \mathrm{kg})$ it had no effect in 14-h withdrawn dependent monkeys; and at higher doses (6.4$12.8 \mathrm{mg} / \mathrm{kg}$ ) caused a mild exacerbation of withdrawal signs. A dose of $25.6 \mathrm{mg} / \mathrm{kg}$ of butorphanol produced convulsions. Nalbuphine exacerbated withdrawal at doses of $4-8 \mathrm{mg} / \mathrm{kg}$, whereas lower doses had no effect. Pentazocine and picenadol were different from the three other compounds in that they neither suppressed nor exacerbated withdrawal at sub-convulsive doses. Pentazocine and picenadol both caused slight stupor at intermediate doses.

The mu antagonist effects of the compounds under investigation were identified in non-withdrawn morphine-dependent monkeys, as summarized in the right-hand column of Table $\mathrm{V}$. Buprenorphine $(0.01-0.32 \mathrm{mg} / \mathrm{kg}$ ) 

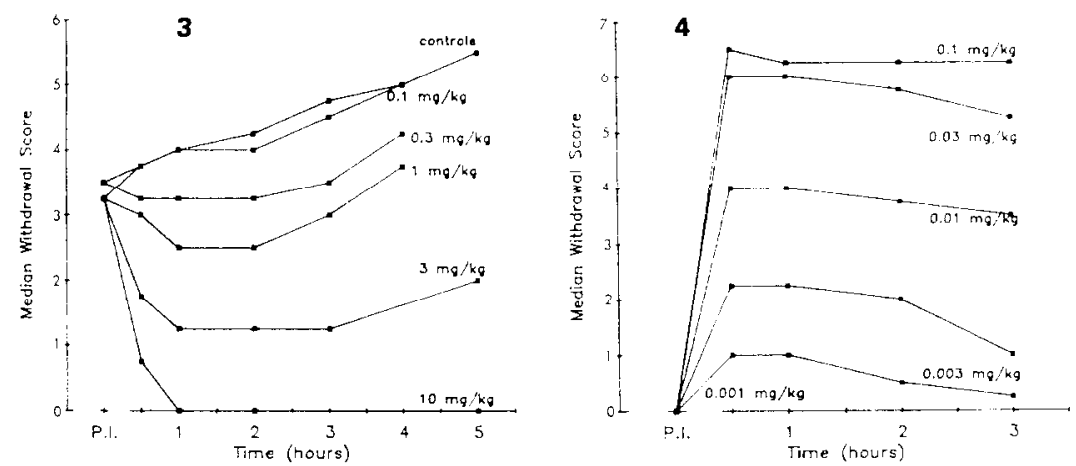

Fig. 3. The effect of single s.c. doses of morphine sulfate in 14-h withdrawn morphinedependent rhesus monkeys ( $n=6 /$ dose) over time. Withdrawal scores were determined according to Table IV. Controls received no treatment. P.I. = pre-injection

Fig. 4. The effect of single s.c. doses of naltrexone $\mathrm{HCl}$ in non-withdrawn morphinedependent rhesus monkeys $(n=6 /$ dose). Withdrawal scores were determined according to Table IV. P.I. = pre-injection.

precipitated withdrawal in a dose-related manner, as did nalbuphine (4-16 $\mathrm{mg} / \mathrm{kg}$ ). However, butorphanol and pentazocine did not elicit withdrawal signs in morphine-dependent monkeys. Picenadol was not tested.

\section{PRIMARY ADDICTION STUDIES}

The propensity of a given compound to produce physiological dependence following chronic administration was judged through primary addiction studies. Three to six drug-naive rhesus monkeys were injected with the test compound every $6 \mathrm{~h}$ at the maximum tolerable dose, with the dose in-

\section{TABLE V}

DOSES (mg/kg, s.c.) OF COMPOUNDS WHICH (1) SUPPRESS 14-H ABSTINENCE OR (2) PRECIPITATE WITHDRAWAL IN MORPHINE-DEPENDENT RHESUS MONKEYS

\begin{tabular}{|c|c|c|}
\hline Compound & $\begin{array}{l}\text { (1) Dose causing } \\
\text { complete suppression }\end{array}$ & $\begin{array}{l}\text { (2) Dose precipitating } \\
\text { moderate withdrawal }\end{array}$ \\
\hline Buprenorphine & - a & 0.3 \\
\hline Butorphanol & - & - \\
\hline Nalbuphine & - & 6.0 \\
\hline Pentazocine & - & - \\
\hline Picenadol & - & Not tested \\
\hline Morphine & 10.0 & - \\
\hline UM 1072 & - & - \\
\hline
\end{tabular}

\footnotetext{
${ }^{\mathrm{a}}$ No suppressing effect on withdrawal signs.
} 
creasing as tolerance developed. The objective of the dosing schedule was to maintain intoxication by the test compound. After 14 and 16 days of chronic drug administration, the monkeys were challenged with a dose of $2 \mathrm{mg} / \mathrm{kg}$ nalorphine and naloxone, respectively. Chronic administration of the test agent continued and the monkeys were again challenged with nalorphine and naloxone $(2 \mathrm{mg} / \mathrm{kg})$ on days 28 and 30 , respectively. Finally, after $31-36$ days of chronic administration, the test agent was completely withdrawn. Signs of withdrawal were noted following nalorphine and naloxone administration, and during natural withdrawal until the monkeys returned to normal.

Morphine and UM 1072 primary addiction studies were performed and are used as an indication of dependence of the mu- and kappa-type, respectively. Morphine, given at a (sub-maximal) dose of $3 \mathrm{mg} / \mathrm{kg}$ every $6 \mathrm{~h}$, caused a rapid development of dependence. Thus, naloxone administration on day 16 of chronic morphine administration produced severe withdrawal, with withdrawal scores of $5-6$. The signs of withdrawal included miosis, an increased rate of respiration, piloerection, vomiting, muscle rigidity and tremor, crying and calling out, fighting, extreme irritability while in their cage (avoidance of contact with other monkeys, disrupted social order and interactions) and during handling (vocalization, avoiding being touched, scratching, biting and staying on the floor), and severe abdominal cramping (i.e. the monkeys protect and hold their stomachs and assume peculiar postures in their cages, and have rigid abdomens when palpated). It should be emphasized that the abdominal cramping is a primary guide in grading morphine withdrawal. Abrupt withdrawal of morphine after 36 days resulted in severe abstinence signs, including convulsions. One out of three monkeys died.

In contrast, chronic UM 1072 administration $(0.05-3.2 \mathrm{mg} / \mathrm{kg})$ did not result in severe dependence. Naloxone administration on day 16 produced signs of general irritability and restlessness (disrupted social order and interactions, avoidance of physical contact with other monkeys, continued pacing and changing of position). A half-yawn/half-retch behavior was frequently seen, as well as piloerection. Although the monkeys appeared pale, spent time lying on their sides, and vocalized during handling, they did not have abdominal defense reactions to palpation. On day 30 of UM 1072 administration, naloxone caused extreme restlessness and irritability. The monkeys paced and shifted positions constantly. Stretching also occurr ed. The half-yawn/half-retch behavior was frequent. This was often associated with a rolling of the tongue within the monkey's mouth. During handling, the monkeys were irritable and combative, but there was no abdominal defense reaction to palpation, and no indication of abdominal muscle cramping. Abrupt withdrawal of UM 1072 resulted in extreme restlessness and irritability, but again there was no abdominal response to palpation. The withdrawal syndrome exhibited in UM 1072 dependent monkeys is qualitatively different from that seen in morphine-dependent monkeys. 
The most distinctive signs of UM 1072 withdrawal which are not generally seen during morphine withdrawal are the half-yawn/half-retch behavior, extreme restlessness (continued pacing), stretching and tongue rolling. The highest withdrawal scores given to UM 1072-withdrawn monkeys were ' $2 \mathrm{~s}$ ' on day 4 of abstinence. However, there were mild convulsions and one out of three animals died. The monkeys appeared normal after 5 days of UM 1072 abstinence. Recently, UM $1072(3 \mathrm{mg} / \mathrm{kg}$ per $6 \mathrm{~h})$ was administered to 6 monkeys for 6 months. None of the monkeys convulsed or died during abrupt withdrawal of UM 1072. Otherwise, withdrawal was qualitatively similar to that seen in the previous investigation (Gmerek, unpublished).

The results of primary addiction studies with the test compounds are summarized in Table VI. The details of each primary addiction study will be discussed in turn below.

Buprenorphine was given every $6 \mathrm{~h}$ at doses increasing from 0.08 to $1.28 \mathrm{mg} / \mathrm{kg}$. There was a rapid development of tolerance to the stupor and muscle relaxation produced by this compound. Nalorphine challenge had no effect in buprenorphine-dependent monkeys. Naloxone caused some piloerection, irritability and restlessness, but not enough to justify withdrawal scores above zero. Abrupt withdrawal of buprenorphine resulted in some restlessness, tremor and tongue movements. However, the monkeys did not protect their abdomens while in their cages, nor was there evidence

\section{TABLE VI}

RESULTS OF PRIMARY ADDICTION STUDIES

\begin{tabular}{|c|c|c|c|c|}
\hline Compound & $\begin{array}{l}\text { Maximum } \\
\text { dose } \\
(\mathrm{mg} / \mathrm{kg} \\
\text { per } 24 \mathrm{~h})\end{array}$ & $\begin{array}{l}\text { Naloxone- } \\
\text { precipitated } \\
\text { withdrawal } \\
\text { score }^{\mathrm{a}, \mathrm{b}}\end{array}$ & $\begin{array}{l}\text { Maximum } \\
\text { withdrawal } \\
\text { score } \\
\text { during } \\
\text { natural } \\
\text { abstinence } \\
c, b\end{array}$ & $\begin{array}{l}\text { Natural } \\
\text { withdrawal } \\
\text { type }\end{array}$ \\
\hline Buprenorphine & 4.8 & None & None & None \\
\hline Butorphanol & 24.0 & $5-6$ & $2-3$ & kappa \\
\hline Nalbuphine & 128.0 & $2-3$ & $2-3$ & $\mathrm{mu}$ \\
\hline Pentazocine & 48.0 & $1-2$ & 3 & kappa \\
\hline Picenadol & 160.0 & $3-4$ & $3-4$ & kappa \\
\hline Morphine & 12.0 & $5-6$ & $6-7$ & $\mathrm{mu}$ \\
\hline UM 1072 & 12.0 & $1-2$ & 2 & kappa \\
\hline
\end{tabular}

\footnotetext{
${ }^{a}$ Naloxone $(2 \mathrm{mg} / \mathrm{kg})$ given on day 30 of chronic administration.

${ }^{b}$ Withdrawal score given according to Table IV.

'Peak withdrawal score observed during abrupt withdrawal.

${ }^{d}$ Withdrawal of the mu or kappa type as defined by that observed following chronic morphine or UM 1072 administration, respectively.
} 
during palpation of abdominal cramping. In essence, there were no observable signs indicative of physiological dependence to buprenorphine.

Butorphanol was given at doses of $0.8-6.4 \mathrm{mg} / \mathrm{kg}$ over a 38 day study. Tolerance developed rapidly to the stupor and muscle relaxation produced by this compound. Nalorphine administration on days 14 and 31 resulted in scratching and general signs of irritability, but abdominal defense reactions never developed. Naloxone, however, elicited severe withdrawal on days 16 and 36 ; the behavior was indistinguishable from that observed in morphine-dependent monkeys. Nevertheless, in contrast to what is seen in morphine-dependent animals, natural withdrawal from butorphanol resulted in only mild signs of abstinence. There was very little abdominal defense reaction during handling of these animals. Butorphanol withdrawal behavior was more of the UM 1072-type than the morphine-type. Maximum withdrawal scores of 2-3 were given at $36 \mathrm{~h}$ of butorphanol abstinence. The monkeys returned to their normal state after 10 days.

Nalbuphine was administered at the dose of $32 \mathrm{mg} / \mathrm{kg}$ every $6 \mathrm{~h}$ for 31 days. Tolerance developed in terms of the duration of the effects of acute nalbuphine (mydriasis, mild stupor and muscle relaxation) and the maximum effect observed after a given dose. Challenge with nalorphine had no effect, but naloxone administration on days 16 and 29 produced severe abstinence behavior. There was only minimal abdominal defense reactions during palpation, but all other signs typical of morphine withdrawal were seen. Abrupt withdrawal of nalbuphine caused morphine-like abstinence behavior, including abdominal defense reactions. Maximum withdrawal scores of $2-3$ were given at $36-48 \mathrm{~h}$ of abstinence. The monkeys returned to normal in about 10 days. A weight loss of $0.3 \mathrm{~kg}$ was observed during the first 3 days of nalbuphine withdrawal; the weight was regained during the next week. No monkeys died.

Pentazocine was given at doses of $2-8 \mathrm{mg} / \mathrm{kg}$ to 3 monkeys for 33 days. The short duration of action of pentazocine required that it be given every $4 \mathrm{~h}$ in order to maintain intoxication. Tolerance developed to pentazocineinduced stupor and muscle relaxation. The monkeys scratched at the site of pentazocine injection. They also were irritable and excited at the time of injection. These signs may be indications of withdrawal occurring between injections. Challenge with naloxone on day 14 resulted in irritability, piloerection, restlessness, an increased rate of respiration and a half-yawn/ half-retch behavior (similar to that seen during UM 1072 withdrawal). Challenge with nalorphine on day 16 caused some sedation in addition to mild kappa-like withdrawal behavior. Naloxone and nalorphine on days 28 and 30 elicited UM 1072-like withdrawal behavior which was more intense than that observed earlier in the study. Scratching, stretching, restlessness, irritability and the half-yawn/half-retch behavior were recorded. Abrupt withdrawal of pentazocine also resulted in abstinence behavior very similar to that seen during UM 1072 withdrawal. Signs of natural withdrawal from pentazocine included irritability, restlessness, scratching, 
stretching, tongue rolling, the half-yawn/half-retch behavior, holding and protecting of the abdomen and abdominal defense reactions during handling. Withdrawal scores peaked at $32 \mathrm{~h}$ of abstinence. The monkeys reverted to their normal state within 1 week.

Picenadol was given to three monkeys at a dose of $10 \mathrm{mg} / \mathrm{kg}$ every $6 \mathrm{~h}$, and then $20 \mathrm{mg} / \mathrm{kg}$ every $8 \mathrm{~h}$. Tolerance developed to picenadol-induced stupor, ataxia, mydriasis and tremors. Nalorphine given on day 14 did not elicit any signs of withdrawal, but may have potentiated picenadol-induced stupor. Naloxone challenge on day 16 produced mile to moderate signs of withdrawal including irritability, apprehension, restlessness, nausea and vomiting and a slight increase in the rate of respiration. On day 21 of picenadol administration, nalorphine caused some signs of irritability and malaise (e.g. lying on side), but withdrawal scores above zero were not given. Naloxone was given on day 23 and produced withdrawal behavior of moderate severity (scores of 3-4). There was no abdominal defense reaction during handling although the monkeys were lying on their sides and protecting their abdomens. Abrupt withdrawal of picenadol after 27 days of administration caused abstinence behavior which was not typical of that seen following chronic morphine administration. The monkeys were irritable, restless and apprehensive. They had an increased rate of respiration, piloerection and tremors. The monkeys displayed tongue rolling but very little abdominal defense reaction to palpation. Curiously, mydriasis remained evident throughout picenadol withdrawal, whereas morphine and UM 1072-withdrawal both cause miosis. Signs of abrupt withdrawal from picenadol peaked at $60-66 \mathrm{~h}$ with withdrawal scores of $3-4$. The monkeys returned to their normal states after $2-3$ weeks.

\section{DISCUSSION}

The overall summary of the compounds under investigation is shown in Table VII. Each test agent will be discussed in turn.

Buprenorphine has mu-like agonist effects in drug discrimination and self-administration tests $[4,8]$ but precipitates withdrawal in morphinedependent rhesus monkeys. Buprenorphine also has been shown to precipitate signs of withdrawal in morphine-dependent patas monkeys, but not in rats [9]. Thus, buprenorphine is a mixed mu agonist-antagonist.

The inability of buprenorphine to produce significant physiological dependence as measured by naloxone-precipitated or natural withdrawal in these studies in similar to what was found in patas monkeys [9] and rats [10], and previously in rhesus monkeys [8]. However, Martin et al. [11] found that multiple intravenous injections of buprenorphine in chronic spinal dogs resulted in a mild but prolonged abstinence syndrome. Buprenorphine also partially suppresses withdrawal in morphine dependent chronic spinal dogs [12] and in 8-h withdrawn morphine dependent rhesus monkeys (Gmerek, unpublished). These studies indicate that buprenorphine does 
TABLE VII

SUMMARY OF THE PROFILE OF EFFECTS OF SELECTED COMPOUNDS IN RHESUS MONKEYS ${ }^{\mathrm{a}}$

\begin{tabular}{|c|c|c|c|c|c|c|}
\hline \multirow[t]{3}{*}{ Compound } & \multicolumn{2}{|c|}{$\begin{array}{l}\text { Shares discriminative } \\
\text { effects with }\end{array}$} & \multirow{3}{*}{$\begin{array}{l}\text { Rate of } \\
\text { Self-Ad- } \\
\text { ministration }\end{array}$} & \multirow{2}{*}{\multicolumn{2}{|c|}{$\begin{array}{l}\text { Effect or with- } \\
\text { drawal in } \\
\text { morphine- } \\
\text { dependent } \\
\text { monkeys }\end{array}$}} & \multirow{3}{*}{$\begin{array}{l}\text { Primary } \\
\text { dependence } \\
\text { natural- } \\
\text { withdrawal } \\
\text { type }\end{array}$} \\
\hline & \multirow[t]{2}{*}{ Morphine } & \multirow[t]{2}{*}{$\begin{array}{l}\text { Ethyl- } \\
\text { ketazocine }\end{array}$} & & & & \\
\hline & & & & $\begin{array}{l}\text { Sup- } \\
\text { presses }\end{array}$ & $\begin{array}{l}\text { Precip- } \\
\text { itates }\end{array}$ & \\
\hline Buprenorphine & Yes & No & High & No & Yes & None \\
\hline Butorphanol & Yes & No & Low & No & No & kappa \\
\hline Nalbuphine & Yes & No & Intermediate & No & Yes & $\mathrm{mu}$ \\
\hline Pentazocine & No & No & Low/high & No & No & kappa \\
\hline Picenadol & $\mathrm{N}^{\prime} \mathrm{I}^{\mathrm{b}}$ & No & Low & No & $\mathrm{NT}^{\mathrm{b}}$ & kappa \\
\hline Morphine & Yes & No & High & Yes & No & $\mathrm{mu}$ \\
\hline UM 1072 & No & Yes & Low & No & No & kappa \\
\hline
\end{tabular}

${ }^{a}$ In tests described in text.

${ }^{b} \mathrm{NT}$, not tested.

have the potential to produce dependence. The dependence-producing capacity of buprenorphine can be demonstrated in rats when buprenorphine pretreatment is followed by substitution with morphine. Thus, naloxoneprecipitated withdrawal signs are observed following a single dose of morphine in rats pretreated with multiple injections of buprenorphine (but not in saline pretreated rats). Buprenorphine thus apparently increases the potential of morphine to induce dependence. It has been suggested that the few signs of withdrawal which can be observed in direct dependence tests with buprenorphine reflect the slow dissociation of this compound from opiate receptors [10].

Butorphanol has discriminative stimulus effects equivalent to etorphine but not to ethylketazocine in rhesus monkeys [4]. Similarly, in rats, butorphanol generalizes to morphine [13] but not to cyclazocine [14]. In squirrel monkeys, however, butorphanol does generalize to cyclazocine [15]. Furthermore, butorphanol exerts kappa-like subjective effects in humans [16]. Butorphanol, like UM 1072, is self-administered by rhesus monkeys at only low rates [4]. It also does not substitute for morphine in morphinedependent monkeys; nor does it precipitate withdrawal. In fact, the antagonist action of butorphanol has not been demonstrated in rhesus monkeys, but it does antagonize morphine in rodents $[17,18]$. Naloxone-precipitated butorphanol withdrawal is severe, but natural withdrawal from butorphanol is mild, and more kappa-like than mu-like. Similarly, when butorphanol is self-administered by morphine post-addict rats, substitution of saline for 
butorphanol results in only mild abstinence signs [19]. In rats, using a schedule-controlled behavior procedure, butorphanol has been classified as a kappa agonist and a mu or kappa antagonist (or partial agonist) [20]. However, in rhesus monkeys, butorphanol cannot be clearly classified as an agonist with selectivity at either kappa or mu receptors and has very weak antagonist activity.

Nalbuphine has the profile of a mu agonist in discrimination, self-administration [4] and primary addiction studies. However, it does not substitute for morphine in morphine-dependent monkeys. Rather, it precipitates morphine-withdrawal. Nalbuphine is thus a typical mixed mu agonistantagonist in rhesus monkeys. Nalbuphine produced a lower level of dependence than morphine or pentazocine, however, in morphine post-addict rats [19].

Pentazocine differs from the other compounds in that it does not have ethylketazocine- [3] or etorphine-equivalent discriminative effects in rhesus monkeys. Pentazocine has idiosyncratic effects in monkeys trained to self-administer codeine. Some monkeys will self-administer pentazocine at high rates, whereas others tend not to self-administer pentazocine. Pentazocine does not suppress or precipitate morphine withdrawal, but induces primary dependence of the kappa type. In fact, this is the only available evidence in the rhesus monkey that pentazocine is a kappa agonist. Similar to the monkeys results, in rats, withdrawal from chronic pentazocine is mild. Unlike monkeys, however, withdrawal in morphine-dependent rats is partially suppressed by pentazocine [21]. The antagonist actions of pentazocine are very weak in the rhesus monkey; however, pentazocine will not antagonize the effect of morphine on schedule-induced responding in monkeys [22] and only at very high doses will participate withdrawal in morphine-dependent monkeys [7]. Pentazocine apparently acts as a mixed kappa agonist-antagonist in the rhesus monkey. Similarly, pentazocine has been classified as a weak mu antagonist and a strong kappa and sigma agonist in the chronic spinal dog [12].

Very little is known about picenadol, the newest of the compounds investigated in this study. It was assumed that picenadol is an opioid, although the observable agonist actions of acutely administered picenadol were resistant to antagonism by naloxone. Picenadol may be similar to pentazocine in that, although it produces primary dependence of the kappa type, it does not occasion drug-appropriate responding in monkeys trained to discriminate ethylketazocine. In a manner also similar to pentazocine, it neither suppresses nor precipitates morphine withdrawal. It is self-administered at only low rates; similar to UM 1072. Picenadol may be a mixed kappa agonist-antagonist with novel additional properties.

\section{REFERENCES}

1 J.H. Woods et al., Mech. Pain Analgesic Compounds (1979) 429.

2 J.H. Woods, A.M. Young and S. Herling, Fed. Proc., 41 (1982) 221.

3 D.W. Hein et al., J. Pharmacol. Exp. Ther., 218 (1981) 7. 
4 A.M. Young et al., J. Pharmacol. Exp. Ther., 229 (1984) 118.

5 A.M. Young, H.H. Swain and J.H. Woods, Psychopharmacology, 74 (1981) 329.

6 G.A. Deneau and M.H. Seevers, Proc. Committee on Drug Addiction and Narcotics, 21 st meeting, 1960, Addendum.

7 J.E. Villarreal, Agonist and Antagonist Actions of Narcotic Analgesic Drugs (1972) 73.

8 N.D. Mello, M.P. Bree and J.G. Mendelson, Pharmacol. Biochem. Behav., 15 (1981) 215.

9 A. Cowan, J.W. Lewis and I.R. MacFarlane, Br. J. Pharmacol., 60 (1977) 537.

10 J. Dum, J. Blasig and A. Herz, Eur. J. Pharmacol., 70 (1981) 293.

11 W.R. Martin, Br. J. Clin. Pharmacol., 7 (1979) 273 S.

12 W.R. Martin et al., J. Pharmacol. Exp. Ther., 197 (1976) 517.

13 H.E. Shannon and S.G. Holtzman, J. Pharmacol. Exp. Ther, 201 (1977) 55.

14 J.M. White and S.G. Holtzman, J. Pharmacol. Exp. Ther., 224 (1983) 95.

15 G.J. Schaeffer and S.G. Holtzman, J. Pharmacol. Fxp. Ther., 201 (1977) 67

16 D.R. Jasinski, Drug Addiction I, 45 (1977) 197.

17 A.W. Pircio et al., Arch. Int. Pharmacodyn. Ther., 220 (1976) 231.

18 U. Filibeck, C. Castellano and A. Oliverio, Psychopharmacology, 73 (1981) 134.

19 G.F. Steinfels, G.A. Young and N. Khazan, Pharmacol. Biochem. Behav., 16 (1982) 167.

20 R.A. Harris, J. Pharmacol. Exp. Ther., 213 (1980) 497.

21 E. Tagashira et al., Japan. J. Pharmacol., 32 (1982) 523.

22 D.A. Downs and J.H. Woods, J. Pharmacol. Exp. Ther., 196 (1976) 298. 